\title{
Molecular Simulations of Porphyrins and Heme Proteins
}

\author{
John A. Shelnutt \\ BECEIVED \\ Biomolecular Materials and Interfaces Department \\ JAN 282000 \\ Sandia National Laboratories \\ OST \\ Albuquerque, NM 87185-1349 \\ and \\ Department of Chemistry \\ The University of New Mexico \\ Albuquerque, NM 87131 \\ For submission to: \\ Journal of Porphyrins and Phthalocyanines
}

Prepared:

November 16, 1999

Sandia is a multiprogram laboratory operated by Sandia Corporation, a Lockheed Martin Company, for the United States Department of Energy under Contract DE-AC0494AL85000. 


\section{DISCLAIMER}

This report was prepared as an account of work sponsored by an agency of the United States Government. Neither the United States Government nor any agency thereof, nor any of their employees, make any warranty, express or implied, or assumes any legal liability or responsibility for the accuracy, completeness, or usefulness of any information, apparatus, product, or process disclosed, or represents that its use would not infringe privately owned rights. Reference herein to any specific commercial product, process, or service by trade name, trademark, manufacturer, or otherwise does not necessarily constitute or imply its endorsement, recommendation, or favoring by the United States Government or any agency thereof. The views and opinions of authors expressed herein do not necessarily state or reflect those of the United States Government or any agency thereof. 


\section{DISCLAIMER}

Portions of this document may be illegible in electronic image products. Images are produced from the best available original document. 


\section{Abstract}

An overview of the use of classical mechanical molecular simulations of porphyrins, hydroporphyrins, and heme proteins is given. The topics cover molecular mechanics calculations of structures and conformer energies of porphyrins, energies of barriers for interconversion between stable conformers, molecular dynamics of porphyrins and heme proteins, and normal-coordinate structural analysis of experimental and calculated porphyrin structures. Molecular mechanics and dynamics are currently a fertile area of research on porphyrins. In the future, other computational methods such as Monte Carlo simulations, which have yet to be applied to porphyrins, will come into use and open new avenues of research into molecular simulations of porphyrins. 


\section{Introduction}

Molecular simulations based on classical mechanics molecular models are useful to porphyrin chemists and materials scientists in a variety of ways. Perhaps the simplest and most useful are simple energy-optimization calculations, which predict porphyrin structures using molecular mechanics (MM) 1. These calculations are particularly helpful, for example, for computer-designing porphyrins possessing tailored structures and desired structural features for purposes of specific chemical or photophysical applications. Besides simple molecular structure, other types of molecular information are obtainable from molecular mechanics calculations if the potential energy surface of the porphyrin is represented accurately enough in the model. For example, molecular mechanics calculations permit the determination of the relative energies of porphyrin conformers when several stable conformers exist. Furthermore, constrained energyoptimization calculations can give good estimates of distortional energies and heights of energy barriers between the stable porphyrin conformers. In some cases, the calculation of a complete potential surface is done by systematically varying the constraints for a pair of structural parameters.

In the last decade, molecular mechanics has become a powerful tool for computing the structure and relative energies of conformers of porphyrins. One of the greatest advantages of molecular mechanics calculations, which are based on a classical mechanical force field, is its computational speed when compared with quantum mechanical methods. Scaling only as $N^{2}$, where $N$ is the number of atoms, molecular mechanics holds an extreme advantage over quantum mechanical methods which scale as $N^{4}$ (Hartree-Fock), $N^{5}$ (density functional theory), or even higher for electron- 
correlation calculations. This speed advantage allows very large porphyrin-based systems to be treated explicitly, for example, including solvent molecules in some calculations or the entire polypeptide of heme proteins. The speed advantage also enables complicated conformational searching algorithms for stable conformers on sometimes very complex and shallow potential energy surfaces. The classical calculations also permit the long molecular dynamics calculations that are required for accurately determining thermodynamic quantities.

Molecular dynamics (MD) calculations solve for the molecular structure as a function of time given an initial structure and set of atomic velocities. The initial velocities are typically assigned to be representative of a chosen temperature and periodically adjusted to maintain constant temperature during the simulation. Dynamics calculations can be used to gain a measure of the molecular conformations that are accessible at a particular temperature. However, the time interval over which molecular dynamics calculations are typically feasible limits the conformations that are reached to those that can be accessed by crossing low energy barriers. Nonetheless, molecular dynamics calculations are useful for calculating a variety of thermochemical quantities such as the free energy. This application of $\mathrm{MD}$ has seen little use at present, but offers a fruitful area of future research.

The first computer simulations of porphyrins were those initiated by Kollman et al. 2, Marques and coworkers 3, and Shelnutt and coworkers 4-7 about a decade ago. Since 1990, there has been well over 200 papers on porphyrins and heme proteins in which molecular modeling was used at some level. These molecular simulations provide chemists with an understanding of the flexibility of the porphyrin ligand itself 
and a conception of the structural influences on porphyrin distortion resulting from metal coordination, axial ligation, peripheral substitution, and the interaction of the porphyrin with its environment. In most cases, the calculations give accurate porphyrin structures that aid in the interpretation of experimental data. They also give molecular shape information that is useful for understanding porphyrin interactions with other molecules and molecular systems. Molecular modeling of supramolecular structures containing porphyrins provides detailed information about non-covalent complexes between the porphyrins and other parts of the superstructure. For quantum calculations, energy-optimized MM structures of porphyrins may provide the initial molecular structures required either for single-point calculations or as a good starting point for quantum-mechanical geometry-optimization calculations.

Many structural and dynamical properties of porphyrins can be obtained by classical molecular simulations, and the ability to predict these properties is useful for many applications of porphyrins in materials science, chemistry, and biology. Molecular mechanics calculations are also especially helpful for interpreting structural and spectroscopic data from proteins that contain porphyrins and hydroporphyrins as functional groups, thus aiding in understanding the biological activity of these important prosthetic groups. For many proteins, the nonplanar heme structures are characteristic of the specific protein type and function 8-10.

Normal-coordinate structural decomposition (NSD) is not a molecular simulation technique in the usual sense, but provides a simple and uniquely useful method for characterizing the calculated and experimentally obtained structures of the porphyrins. As such, NSD plays an important role in utilizing and evaluating the structures obtained 
from $\mathrm{MM}$ and $\mathrm{MD}$. The distortion of a porphyrin macrocycle given in terms of the symmetric normal coordinates of a reference square-planar macrocycle provides a uniquely informative description of its structure. Because the porphyrin deformations typically occur mostly along the lowest-frequency normal coordinates, the description of the porphyrin structure is usually simplified. This is because the displacements along only a few of the normal coordinates accurately define the distortion. The results of NSD analyses of well over 1,200 hemes contained in in the more than 425 hemeproteins currently in the Protein Data Bank 11,12 are available at our website at http://jasheln.unm.edu. The NSD results for these protein X-ray and NMR structures reveal remarkably consistent heme structural motifs, suggesting a part for nonplanar porphyrin macrocycle structure in the biological function of many heme proteins.

Detailed examination of the NSD results for the X-ray structures of hemeproteins has delineated a variety of structural effects of natural amino acid sequence variations, mutations, axial ligation, and other protein-induced differences in the conformation of the heme, thus tying the primary, secondary, and tertiary structure of the protein moiety to the conformation and function of the heme. In the case of the mitochondrial cytochromes $c$, a structural mechanism by which the protein produces the moderate ruffling of the heme skeleton was suggested by molecular mechanics calculations and the NSD results 8-10. NSD characterization of the hemes of other proteins will undoubtably lead to other detailed mechanisms by which protein structure regulates heme conformation and function.

\section{Results and Discússion}

By far the most common goal of molecular simulations is the determination of 
the minimum energy points on the molecular potential energy surface. These points on the energy surface define the stable conformers of the molecule, and of special interest is the conformer with the lowest energy (global minimum). The relative energies of these stable conformers determine which are thermally accessible. In fact, it has only recently been recognized that multiple conformers can exist for a porphyrin. These conformers may play a role in the chemistry, photochemistry, and biological function of hemes and chlorophylls in proteins. In addition, because there are usually several possible configurations of the peripheral substituents of the porphyrin, multiple stable conformations are frequently observed for highly substituted and sterically crowded porphyrins. Multiple conformers may also occur for biological porphyrins because of several potential energy minima can result from the protein environment. In the confines of the protein, the relative energies of these porphyrin conformers can be altered by the protein or the state of the porphyrin itself, as can the barriers for interconversion between conformers. The energy barriers between porphyrin conformers have been calculated using constrained energy-optimization calculations.

Between 1988 and 1991, Shelnutt and coworkers initiated a series of investigations using molecular mechanics along with $\mathrm{X}$-ray crystallography, and resonance Raman and NMR spectroscopies to investigate a series of nonplanar nickel dodecasubstituted porphyrins that are highly distorted because of the severe crowding of peripheral substituents 1,4,7. POLYGRAF software (MSI) was used with a force field based on experimental results and developed specifically for energy-optimization calculations of porphyrins. Subsequently, many molecular mechanics calculations of porphyrin and hemeprotein systems have been performed using this porphyrin force 
field. In much of this work, porphyrin structures that agree with the available X-ray structures have been alculated using this force field. Furthermore, calculated energies of porphyrin conformers have steadily improved with refinement of the initial force field 13.

Medforth et al. 14 evaluated the predictions of the porphyrin force field for a variety of different modes of distortion for sterically constrained free-base and metal porphyrins and extended its use to analysis of the dynamics of porphyrin structure, especially the relative populations of stable conformers and the barriers to interconversion between them. For example, the relative energies of the different conformers obtained from the variety of quasi-axial/equatorial orientations of the pentyl arms of $\mathrm{Ni}\left(\mathrm{TC}_{5} \mathrm{TC}_{5} \mathrm{P}\right)$ were calculated, and the calculated conformer energies allowed the types of coexisting conformers and their relative populations apparent from the solution NMR spectra to be rationalized 14.

Molecular modeling often results in a distorted porphyrin structure that needs to be describable in the most simple and meaningful way possible. Similarly, porphyrin Xray crystal structures often show complicated distortions from nominal $\mathrm{D}_{4 \mathrm{~h}}$ macrocyclic symmetry that seemingly defying simple description. Structural analysis using normalcoordinate structural decomposition provides the needed framework for simple quantification of the calculated or experimentally obtained porphyrin structures. The $\mathrm{X}$ ray crystal structures of more than a hundred synthetic metalloporphyrins have been analyzed using NSD 9. Perhaps the most revealing use of NSD is in characterizing the asymmetric porphyrin environment in proteins. The asymmetric protein interactions with the porphyrin lead to heme distortions, and NSD provides an easy to understand 
portrayal of the macrocycle distortion. A simple bar graph of the displacements, usually for only a few of the normal coordinates, accurately characterizes the structure and clearly brings out the similarities and differences between structures 10,15-17. The displacements along these fundamental symmetric displacements have recently been related to perturbation energies obtained from Raman dispersion spectroscopy 18.

Given the great variety of heme distortions occurring in heme proteins, it was surprising to find that in many cases these distortions are conserved for the same proteins from different species and organisms. Conservation has been demonstrated for mitochondrial cytochromes $c$, cytochromes $c$ ', peroxidases, and other heme proteins 10 . In some cases, the conformation is conserved for all known crystal structures of a particular protein. For example, the hemes of all of the more than 70 peroxidases and their mutants are predominately saddled 19.

Probably the best example of how NSD analysis of structures calculated by molecular mechanics is a study of the origin of nonplanar heme distortions in tetraheme ferricytochromes $c_{3} 20$. NSD analysis of the individual hemes of the crystal structures of these proteins show remarkable similarities from organism to organism even though there is no sequence identity other than the cysteines of the protein linkages and the histidines acting as axial ligands 10. To discover the origin of the distortion, Ma et al.20 carried out a series of energy-optimization calculations, which included various parts of the protein fixed at the atomic positions in the crystal structures, to determine the influence of the protein segments on the heme distortion. It was found that the largest symmetric deformations of the energy-minimized heme structures well match those of the crystal structures when only the fingerprint peptide (CXYCH or CWXYZCH) 
covalently linking the heme to the protein is included in the calculations. Including less of the protein gave poor agreement, and adding more amino acids had little effect.

Probably one of the most complete early molecular mechanics studies of ruffling of porphyrins was carried out by Munro et al. 21. The authors used a version of MM2(87) modified to include the metal and phenyl atom types, where the new atom parameters were obtained by statistical comparisons of a set of calculated and observed reference structures. With the exception of very small and very large metal ions, the standard force constants of MM2(87) together with the determined unconstrained bond lengths and force constants for the metals are capable of predicting the structures of metalloporphyrins reasonably well. Using the MM2-based force field, the effect of metal ion size on porphyrin geometry was investigated first by examining the energy as a function of unconstrained metal-nitrogen bond length. Subsequently, Munro et al. 22 developed a force field specifically for low-spin $\mathrm{Fe}(\mathrm{II})$ porphyrin complexes and investigated this question in detail. For meso-tetraarylporphyrins, Munro et al. also found that the porphyrin geometry depends on the perpendicular orientation of the axial ligands and the distribution of steric bulk of the substituents. Either increasing the steric bulk of the meso substituents (phenyl $<2,6-\mathrm{Cl}_{2}$-phenyl $<$ mesityl) or the axial ligands (pyridine $<$ (4)5-MeImH $<1,2-\mathrm{Me}_{2}-\operatorname{Im}<\mathrm{Bz} \operatorname{ImH}<2-\mathrm{MeBzImH}$ ) leads to a more ruffled macrocycle.

Marques et al. 23 developed parameters for $\mathrm{Fe}(\mathrm{II})$ and $\mathrm{Fe}(\mathrm{III})$ porphyrins in various Fe spin and coordination states using 124 porphyrin reference structures from the Cambridge Structural Database. The strain-free bond lengths and angles were arrived at by trial and error to reproduce as accurately as possible the structures of the 
chosen iron porphyrins. They then used the force field to investigate conformation of intermediate-spin $\mathrm{Fe}(\mathrm{TPP})$. Using the generic shape algorithm for ring structures developed by Gerber et al. 24 and a quenched dynamics technique, a ruffled and a planar conformer were found with almost the same minimum energies.

Molecular simulation of entire hemeproteins is a rich and active area of research. The work of Prof. Rebecca S. Wade is representative of recent work in this area 25-27. In most cases, the molecular modeling of hemoproteins focuses on the protein component instead of the structure and dynamics of the heme itself. The emphasis is typically on the dynamics and structure of the protein component, the diffusion of small molecules in the protein matrix, the cooling and relaxation dynamics of the protein and heme, and the use of molecular mechanics in refinement procedures for X-ray crystallographic and NMR structural determinations. NSD analysis of the heme in MD trajectories allows the structure of the porphyrin to become the central theme of these studies.

\section{Conclusions and the Future}

Molecular mechanics calculations have a demonstrated history of success in predicting the structure and dynamics of porphyrins and heme proteins. Mainly in the last decade, researchers have focused on the properties of the porphyrin macrocycle itself, finding astonishing flexibility, richness of structural response to local - environment, and remarkable dynamical properties. The prospect for improving the accuracy of MM force fields specifically for porphyrins is great, especially for obtaining

accurate force fields derived from $a b$ initio quantum mechanical calculations of the normal coordinates. 
Normal-coordinate structural decomposition provides a unique means for describing even highly asymmetric porphyrin distortions in a simple and useful manner. It is unique in that it is simply related to the macrocyclic distortion energies. The NSD method can be utilized to analyze both crystal and NMR experimental structures as well as those calculated my molecular mechanics, molecular dynamics, and quantum mechanical structure optimizations. It can be generally applied to porphyrin, metalloporphyrins, and in some cases to hydroporphyrins. With some modification, NSD could be applied to other porphyrin-related compounds as well.

The prospects for the future use of $\mathrm{MM}$ and $\mathrm{MD}$ methods in porphyrin studies are also great. The recent discovery of the role of the protein in causing distortions of the macrocycle hemeproteins on the order of $1 \AA$ and the now demonstrated role of porphyrin distortions in altering the physical and chemical properties point to an increasing emphasis on these aspects of porphyrin chemistry for understanding biological function. $\mathrm{MM}$ and $\mathrm{MD}$ calculations of all types will be important computational tools in discovering the true importance of these porphyrin distortions. Molecular simulations will be especially important in understanding the energetics of interconversions between stable porphyrin conformers, which may be difficult to observe directly by experimental techniques. The calculation of thermodynamic properties by $\mathrm{MD}$ and Monte Carlo methods is virtually unexplored and yet offers many potential benefits.

The ability to quickly and easily analyze porphyrin structures with NSD enables novel statistical analyses of large groups of structures, for example, all hemes in reduced and oxidized hemeproteins. In fact, the NSD method is so new that few of its potential 
uses have yet been exploited. .

\section{References}

1 Shelnutt JA, Medforth CJ, Berber MD, Barkigia KM, Smith KM. J. Am. Chem. Soc. 1991; 113:4077.

2 Kollman PA, Grootenhuis, P. D. J., Lopez, M. A. Pure Appl. Chem. 1989; 61:593.

3 Hancock RD, Weaving JS, Marques HM. J. Chem. Soc., Chem. Commun. 1989:1176.

4 Medforth CJ, Berber MD, Smith KM, Shelnutt JA. Tetrahedron Lett. 1990; 31:3719.

5 Alden RG, Ondrias MR, Shelnutt JA. J. Am. Chem. Soc. 1990; 112:691.

6 Shelnutt JA. J. Phys. Chem. 1989; 93:6283.

7 Shelnutt JA, Stohl FV, Granoff B Computer-Aided Molecular Design of AlkaneActivation Catalysts; Vorres, K. S., Ed.; Argonne National Latoratory: Argonne, IL, 1988; Vol. 33, pp 479.

8 Hobbs JD, Shelnutt JA. J. Prot. Chem. 1995; 14:19.

9 Jentzen W, Song XZ, Shelnutt JA. J. Phys. Chem. B 1997; 101:1684.

10 Jentzen W, Ma JG, Shelnutt JA. Biophys. J. 1998; 74:753.

11 Abola EE, Bernstein FC, Bryant SH, Koetzle TF, Weng J Protein Data Bank; Allen, F. H., Bergerhoff, G. and Sievers, R., Ed.; Data Commission of the International Union of Crystallography: Bonn/Cambridge/Chester, 1987, pp 107.

12 Abola EE, Sussman JL, Prilusky J, Manning NO Protein Data Bank Archives of Three-Dimensional Macromolecular Structures; Carter Jr., C. W. and Sweet, R. M., Ed.; Academic Press: San Diego, 1997; Vol. Vol. 277, pp 556.

13 Song XZ, Jentzen W, Jia SL, Jaquinod L, Nurco DJ, Medforth CJ, Smith KM, Shelnutt JA. J. Am. Chem. Soc. 1996; 118:12975.

14 Medforth CJ, Senge MO, Smith KM, Sparks LD, Shelnutt JA. J. Am. Chem. Soc. 1992; 114:9859.

15 Jentzen W, Song X, Shelnutt JA. Biophys. J. 1996; 70:A153.

16 Shelnutt JA, Song XZ, Ma JG, Jia SL, Jentzen W, Medforth CJ. Chem. Soc. Rev. 1998; 27:31.

17 Shelnutt JA Molecular simulations and normal-coordinate structural analysis of porphyrins and heme proteins; Kadish, K. M., Smith, K. M. and Guilard, R., Ed.; Academic Press: New York, 2000; Vol. 7, pp 167.

18 Schweitzer-Stenner R, Stichternath A, Dreybrodt W, Jentzen W, Song X-Z, Shelnutt JA, Nielsen OF, Medforth CJ, Smith KM. J. Chem. Phys. 1997; 107:1794.

19 Howes BD, Schiodt CB, Welinder KG, Marzocchi MP, Ma J-G, Zhang J, Shelnutt JA, Smulevich G. Biochemistry 1999:submitted.

20 Ma J-G, Zhang J, Franco R, Jia S-L, Moura I, Moura JJG, Kroneck PMH, Shelnutt JA. Biochemistry 1998; 37:12431.

21 Munro OQ, Bradley JC, Hancock RD, Marques HM, Marsicano F, Wade PW. J. Am. Chem. Soc. 1992; 114:7218.

22 Munro OQ, Marques HM, Debrunner PG, Mohanrao K, Scheidt WR. J. Am. 
Chem. Soc. $1995 ; 117: 935$.

23 Marques HM, Munro OQ, Grimmer NE, Levendis DC, Marsicano F, Pattrick G, Markoulides T. J. Chem. Soc., Faraday Trans. 1995; 91:1741.

24 Gerber PR, Gubernator K, Muller K. Helv. Chim. Acta 1988; 71:1429.

25 Wade RS, Castro CE. Chem Res Toxicol 1990; 3:289.

26 Oshea SK, Wang W, Wade RS, Castro CE. J. Org. Chem. 1996; 61:6388.

27 Wade RS, Castro CE. Chem Res Toxicol 1996; 9:1382. 